\title{
COLONIZAÇÃO DE POMACEA HAUSTRUM (REEVE, 1856) EM LOCALIDADE COM ESQUISTOSSOMOSE MANSONI: BALDIM, MG (BRASIL). (PROSOBRANCHIA, PILIDAE) *
}

Roberto Milward-de-Andrade ** Omar dos Santos Carvalho *:*

RSPUB9/453

Milward-De-Andrade, R. \& Carvalho, O. dos S. Colonização de Pomacea haustrum (Reeve, 1856) em localidade com esquistossomose mansoni: Baldim, MG (Brasil). (Prosobranchia, Pilidae). Rev. Saúde públ., S. Patllo, 13: $92-107,1979$.

REsumo: Na localidade de Baldim, MG, Brasil, foram introduzidos, em agosto de 1972, 5.421 exemplares de Pomacea haustrum (Prosobranchia, Pilidae) em 5 córregos e 2 valas, nos quais predominavam Biomphalaria glabrata (Say, 1818) e, secundariamente, B. straminea (Dunker, 1848). Entre 1968 e 1971, os indices de infeção da espécie B. glabrata por Schistosoma mansoni oscilaram de $2,1 \%$ a $11,9 \%$. Em nenhum momento foram capturados B. straminea liberando cercárias daquele trematódeo. Após a introdução do pilideo, apenas uma única vez detectou-se $2(0,8 \%)$ B. glabrata positivas. Observou-se decréscimo populacional de planorbineos e atmento de densidade de pomácea até 20,0 e 121,6 exemplares $/ \mathrm{m}^{2}$ em córregos e valas, respectivamente. A estimativa da densidade de P. haustrun foi feita através do método dos "quadrats". Foram coletados, de junho de 1968 a julho de $1972,65,2 \%$ (1.526) dos planorbineos. Porém, após a introdução do predador-competidor, foram registrados os seguintes dados: $1976,15 \%$ (352); em 1977, 16,1\% (377) e, em 1978, apenas 3,7\% (87) do total dos exemplares capturados. As pomáceas, transferidas do ambiente lenitico (Sete Lagoas, MG), adaptaram-se às coleções lóticas de Baldim e foram capazes de substituir as populações originais de $\mathrm{B}$. glabrata em vários biótopos, ou tornaram-se, pelo menos, dominantes, sem danos visiveis para os novos ecossistemas. Acredita-se que em outras situaçóes análogas, Pomacea haustrum (Reeve, 1956) - e, por extensäo, P. lineata (Spix, 1827), P. canaliculata (Lamark, 1822) e outras do mesmo táxon - poderão ser utilizadas, com sucesso, no controle biológico dos hospedeiros intermediários de Schistosoma mansoni. lógico.

UNITERmos: Pomacea haustrum. Esquistossomose mansônica, controle bio-

* Trabalho parcialmente subvencionado pelo CNPq. Apresentado à 29ạ Reunião anual da SBPC, São Paulo, SP, julho/1977.

* Do Centro de Pesquisas "René Rachou"/FIOCRUZ - Caixa Postal 1748 - 30000 - Belo Horizonte, MG - Brasil e da Universidade Federal de Minas Gerais.

* Do Centro de Pesquisas "René Rachou"/FIOCRUZ. 
MILWARD-DE-ANDRADE, R. \& CARVALHo, O. dos S. Colonizaçăo de Pomacea haustrum (Reeve, 1856) em localidade com esquistossomose mansoni: Baldim, MG (Brasil). (Prosobranchia, Pilidae). Rev. Saúde puibl., S. Paulo, 13:92-107, 1979.

\section{I N T R O D U Ç $\mathrm{O}$}

Assinalada como provável predador e competidor de planorbíneos em condiçōes naturais, o pilideo Pomacea haustrum teve, posteriormente, demonstrada sua capacidade de destruir ovos e formas juvenis de Biomphalaria glabrata (Milward-de-Andrade ${ }^{* 17,20-23}$ ).

A seguir, novas investigações foram projetadas (Milward-de-Andrade **) no sentido de ampliar os conhecimentos anteriormente disponiveis (Lopes, ${ }^{12-14}$ Scott, ${ }^{31}$ Fausto $\left.F^{04,5}\right)$ e as mais recentes informações adquiridas sobre a biologia e a ecologia do mencionado prosobrânquio (Milward-de-Andrade,16,18,19,24 Milward-de-Andrade e Guimarães,26,28; Milward-de-Andrade e Carvatho ${ }^{25}$; Milward-de-Andrade e col.29,30; Carvalho e col. ${ }^{2}$; Guimarães ${ }^{\text {) }}$.

Registra-se entretanto, que observaçôes mais antigas, conduzidas em Porto Rico, não foram encorajadoras (Ferguson e col.6), contrariamente pois, a resultados promissores assinalados entre nós, como mencionado, ao lado, sem embargo, de limitação registrada (Milward-de-Andrade ${ }^{24}$ ).

Outra espécie do mesmo gênero - $\mathrm{Po}$ macea lineata (Spix, 1827) -, mostrou-se também promissora no controle biológico de planorbineos, em laboratório (Matthiesen ${ }^{15}$ ).

Uma vez transposta de ambiente lenítico para biótopo lótico, pretendia-se acompanhar, ao logo do tempo, o processo de colonização do pilídeo em questão. Infelizmente, impostas limitaçōes de infraestrutura indispensável não permitiram 0 acúmulo e registro dos dados pretendidos. Sem embargo, algumas informaçōes científicas de interesse foram obtidas e encontram-se adiante mencionadas.
A cidade de Baldim - integrada à Regiâo Centro-Oeste (Zona Metalúrgica de Minas Gerais) - tem como coordenadas geográficas $19^{\circ} 16^{\prime} 48^{\prime \prime}$ latitude sul e $43^{\circ} 56^{\prime} 54^{\prime \prime}$ longitude oeste, de Greenwich. Encontra-se cerca de $100 \mathrm{~km}$ ao norte de Belo Horizonte $(M G)$, numa altitude de $655 \mathrm{~m}$; tem clima mesotérmico úmido, com inverno seco e temperatura do mês mais quente superior a $22^{\circ} \mathrm{C}$ - enquadrando-se, pois, no tipo Cwa da conhecida classificação de Koeppen ${ }^{11}$.

Em 1974, o município contava com 9.362 habitantes, 1.540 dos quais ocupavam 458 prédios existentes na sede municipal. Desse último total, $55 \%$ (256) encontravam-se ligados à rede de abastecimento d'água $\mathrm{e}$ somente $5 \%$ (23) à uma pequena rede de esgoto***, cujo destino final, ainda no perimetro urbano, é o chamado Córrego Grande, fluindo, pois, à céu aberto e sem qualquer tratamento prévio.

A fitofisionomia geral dos $514 \mathrm{Km}^{2}$ abarcados pelo municipio de Baldim é do tipo dito cerrado, "sensu lato" (Coutinho ${ }^{3}$ ), porém, de há muito degradado. No justo ponto em que se encontra a cidade, observam-se pequenos e estreitos vales cortados por permanentes veios d'água, que percorrem topografia muito pouco acidentada. Dessa forma, o deslocamento da massa líquida, máxime no periodo seco ("inverno"), é lento.

A estação chuvosa estende-se de outubro a março ("verão") com cerca de $95 \%$ da precipitação anual, que nos meses de abril a setembro ("inverno") raramente ultrapassa o total de $40 \mathrm{~mm}$.

Não contando com posto meteorológico, o dado registrado (pelo Departamento Na-

- e também em pesquisa realizada por esse autor, em 1965, sobre "Predação de Pomacea haustrum sobre ovos e formas jovens de Biomphalaria glabrata". Dados inéditos.

* Projeto apresentado ao Conselho Nacional de Ciencia e Tecnologia (CNPq), em 1975 (Proj. SIP, 08/123), por Roberto Milward-de-Andrade, sob o título: "Biologia e ecologia de Pomacea haustrum (Reeve, 1856): Sua utilização no controle biológico dos hospedeiros intermediários do Schistosoma mansoni".

** Dados extraidos dos arquivos do IBGE, Belo Horizonte, 1974. 
MILWARD-DE-ANDRADE, R. \& CARVALHO, O. dos S. Colonização de Pomacea haustrum (Reeve, 1856) em localidade com esquistossomose mansoni: Baldim, MG (Brasil). (Prosobranchia, Pilidae). Rev. Saúde públ., S. Paulo, 13:92-107, 1979.

cional de Meteorologia) na vizinha cidade de Sete Lagoas, indicou 1.308,00 $\mathrm{mm}$ como precipitação normal, para o período de 1961-1977.

Desde longa data, a localidade de Baldim é reconhecida como foco ativo da helmintose em referência. Assinala-se que um então proposto projeto de pesquisa "destinado a contribuir para o esclarecimento de alguns aspectos epidemiológicos e profiláticos da esquistossomose mansoni, levando em consideração sobretudo a eventual possibilidade de controle daquela endemia, através do tratamento em massa da população humana e da aplicação de "Bayluscide", realizando-se, concomitantemente, esclarecedora atividade de educação sanitária junto a população escolar e adulta", foi desenvolvido - em particular, de julho/ 1968 a agosto/1970 (Milward-de-Andrade, e $\left.\operatorname{col} .^{30}\right)$.

Acrescente-se, ainda, que informaçōes relacionadas à terapêutica clínica da população urbana foram anteriormente apresentadas (Katz e col. ${ }^{10}$ ), sendo realizada, posteriormente, avaliação da aplicação das drogas "Niridazole" e "Hicanthone" $\left(\mathrm{Katz}^{9}\right)$.

No presente artigo, registram-se dados numéricos, de 1968 a 1978 , sobre a população do hospedeiro local de Schistosoma mansoni Sambon, 1907 e estimativas da população atual do prosobrânquio Pomacea haustrum intencionalmente introduzido na localidade, pelos autores, em agosto de 1972. Procura-se, ademais, correlacionar a redução populacional de Biomphalaria glabrata, espécie autóctone, com a atividade predadora-competidora do pilídeo nomeado.

\section{MATERIAL E METODOS}

1 - Cursos d'água - Na localidade de Baldim foram identificados cinco córregos permanentes e cinco valas, três clas quais surgiram e/ou desapareceram no decorrer dos anos de 1968 a 1978.
A denominação de cada curso e suas extensões respectivas encontram-se mencionadas na Tabela 1. Pode-se, por outro lado, apreciar a localização segundo o plano urbanístico da cidade (Fig. 1).

\section{2 - Captura e exame de planorbineos -} Durante os anos mencionados, a área foi visitada e pesquisada em treze ocasiões diferentes. Os espécimens de bionfalária capturados foram dimensionados e examinados no laboratório, em Belo Horizonte, pelo processo de esmagamenteo entre lâminas de vidro.

As coletas foram executadas com concinas metálicas, perfuradas lateralmente e no funclo, de $25 \mathrm{~cm}$ de diâmetro e ligadas a hastes de madeira com cerca de $1,20 \mathrm{~m}$ de comprimento.

Adotou-se o critério de, a cada dez passos, dar dez conchadas - colocando-se em pequenos sacos plásticos os exemplares recolhidos.

Os registros de dados ecológicos de campo foram lançados em fichas cartonadas, preparadas para os trabalhos de laboratório de ecologia, as quais encontram-se devidamente ordenadas em arquivo.

A última coleta de bionfalárias foi realizada concomitantemente à estimativa da população atual de pomáceas - capturando-se os exemplares existentes nas áreas ("quadrats") de $250 \mathrm{~cm}^{2}$, delimitadas por quatro pequenas hastes de madeira de 50 $\mathrm{cm}$ de comprimento.

Nos córregos, os "quadrats" foram localizados a cada cem passos, a partir de acidentes identificáveis: pontes e desembocaduras com outros cursos. Assim, nessas coleções hidricas, foram locados de seis a nove pontos de capturas. As estimativas realizadas nas quatro valas ora existentes corresponderam a cinco medidas (amostras) em cada uma delas (Tabela 3). Cada ponto censado foi locado a 50 passos um do outro, aproximadamente. 
MILWARD-DE-ANDRADE. R. \& CARVALHO, O. dos S. Colonização de Pomacea haustrum (Reeve, 1856) em localidade com esquistossomose mansoni: Baldim, MG (Brasil). (Prosobranchia. Pilidae). Rer. Saúde píbl., S. Paulo, 13:22-107, 1979.

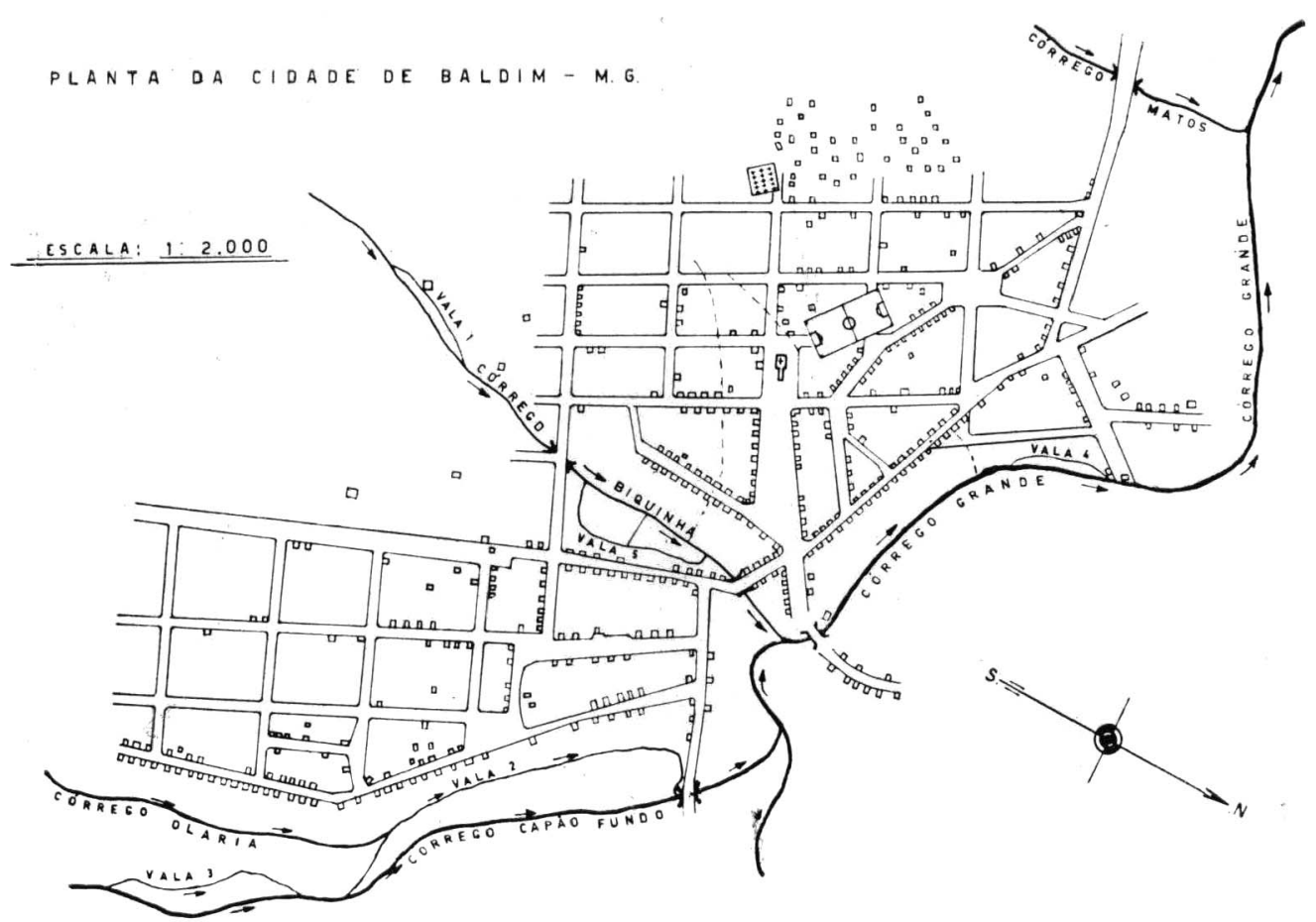

Fig. 1 - Baldim. MG. Planta da cidade, indicando os diferentes cursos d'água (córregos e valas) com populaçóes autóctones de Biomphalaria glabrata e B. straminea.

3 - Pilideos introduzidos na área - Os exemplares de pomáceas distribuidos nos cursos hídricos de Baldim foram capturados na Lagoa Paulino situada no centro urbano da cidade de Sete Lagoas, MG. Naquele biótopo, sempre negativo para bionfalárias, foram feitas duas coletas: 3 e 14/agosto/ 1972, transportando-se o material para Belo Horizonte - onde foi dimensionado e, um a dois dias após, transportado e imediatamente introduzido nos cursos d'água de Baldim.

$\mathrm{Na}$ primeira captura foram colecionados 2.325 exemplares assim considerados: 300 com $40 \mathrm{~mm}$ de altura e $32 \mathrm{~mm}$ de diâmetro; 466 com $39: 29 \mathrm{~mm} ; 477$ com $32: 28 \mathrm{~mm}$; 566 com $30: 26 \mathrm{~mm} ; 149$ com 26:21 mm; e, finalmente, 367 com $25: 20 \mathrm{~mm}$, respectivamente.

O trabalho realizado onze dias depois resultou na coleta de 3.284 novos espécimens, ou seja: 66 com $43: 35 \mathrm{~mm} ; 626$ com $38: 32 \mathrm{~mm} ; 414$ com $35: 28 \mathrm{~mm} ; 1.178$ com 25:20 mm e finalmente, 1.000 com $15: 11$ $\mathrm{mm}$, respectivamente, de altura e diâmetro das conchas.

Com exceção de 34 exemplares da primeira captura e 154 da segunda - mortos entre a coleta e a introdução - todos os demais 5.421 foram distribuídos nos córregos e valas existentes, em 1968, em Baldim.

Assinale-se que não houve preocupação em verificar o sexo dos pilídeos; pois, uma vez retraido para o interior da respectiva 


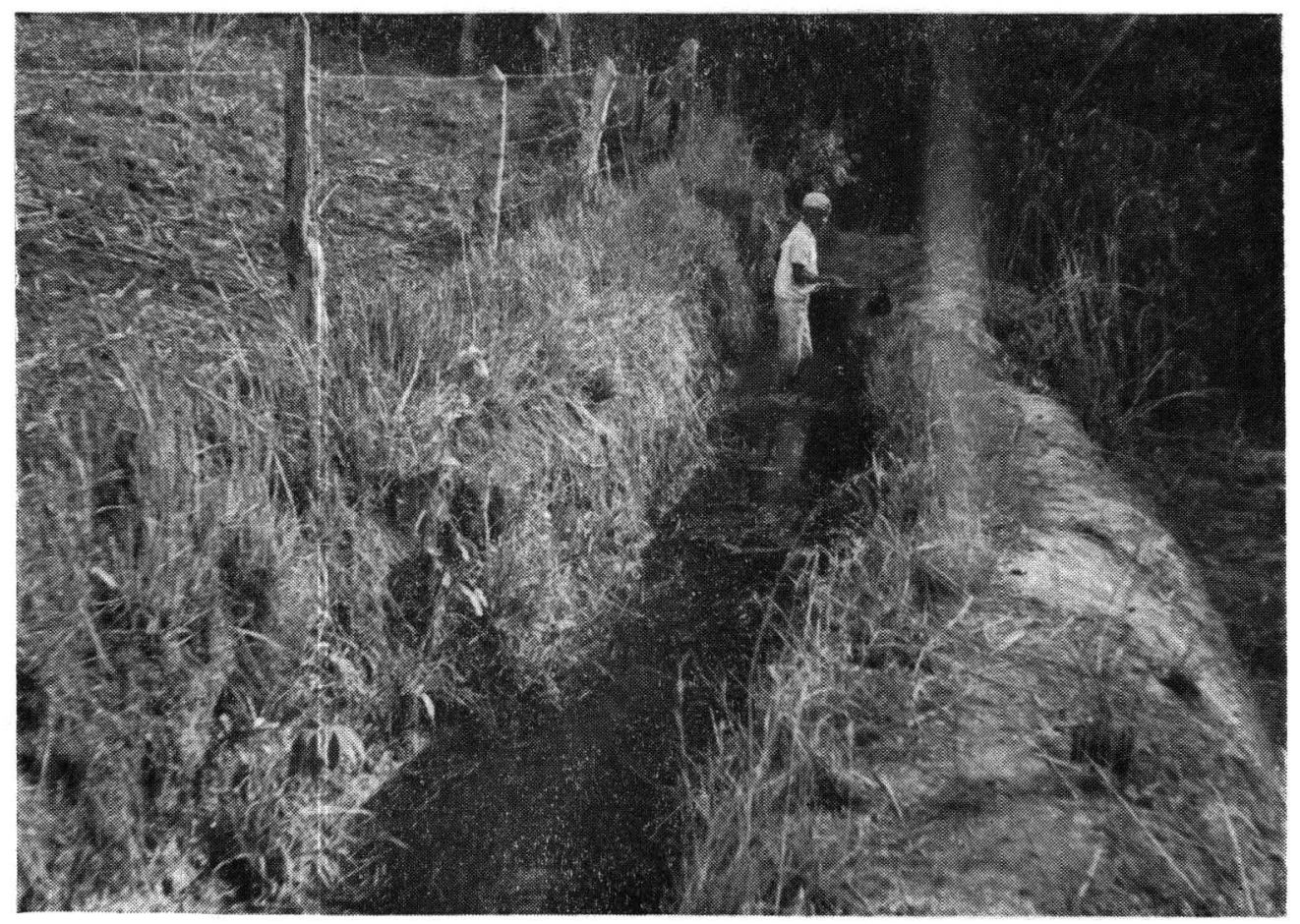

Fig. 2. - Baldim. MG. Vala no 3, negativa para bionfalaria, mas colonizada por Pomacea haustrum a partir de exemplares introduzidos no Córrego Capão Fundo (ver "croquis").

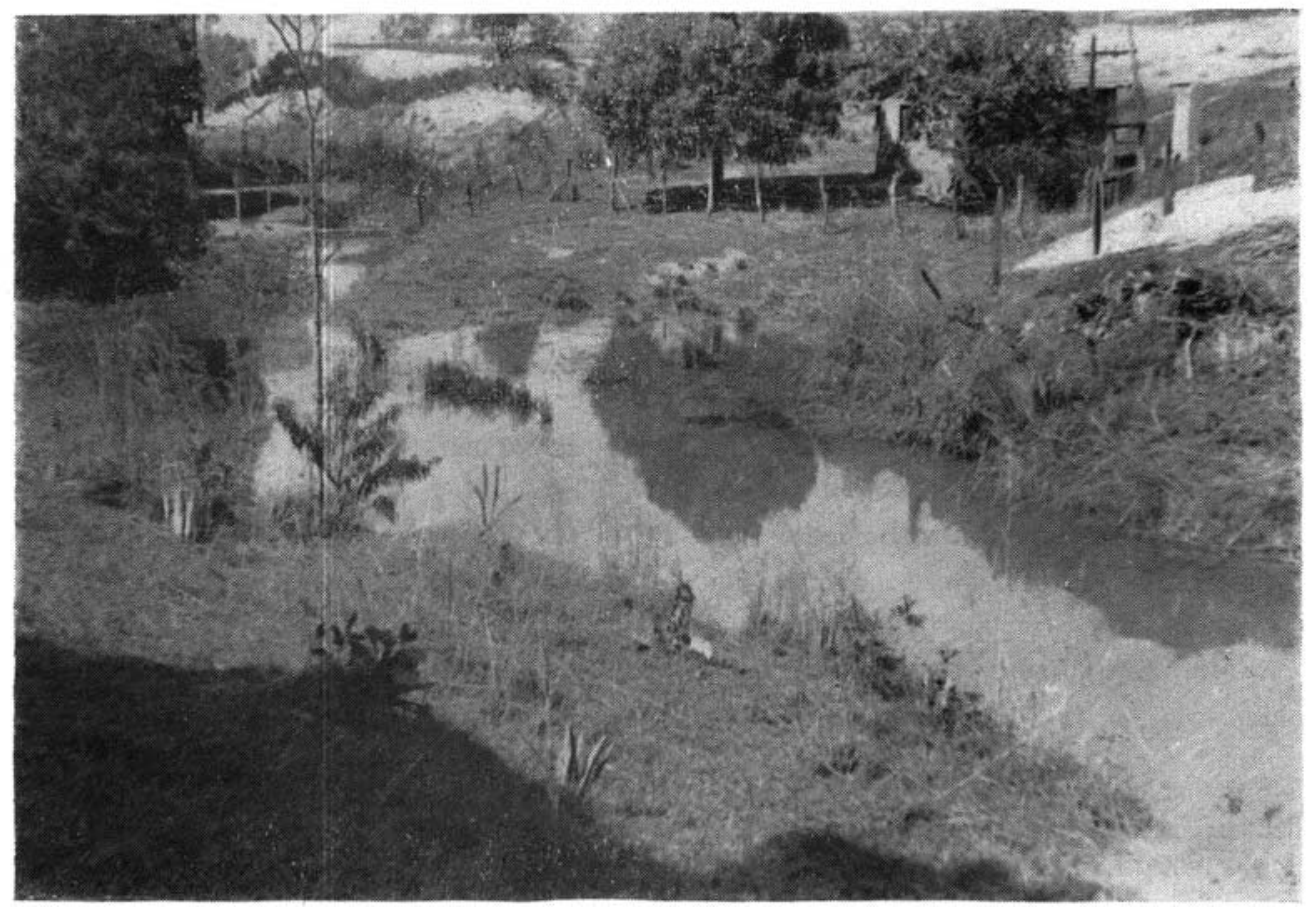

Fig. 2 - Baldim, MG. Córrego Biquinha. Curso d'água no qual foram introduzidos exemplares de Pomacea haustrum para controle da população autóctone de Biomphabaria glabrata. 
MILWARD-DE-ANDRADE, R. \& CARVALHO, O. dos S. Colonização de Pomacea haustrum (Reeve. 1856) em localidade com esquistossomose mansoni: Baldim. MG (Brasil). (Prosobranchia. Pilitae). Rer. Saride públ., S. Paulo, 13:92-107, 1979.

concha, torna-se às vezes penosa a operação de abertura forçada do epérculo, podendo, inclusive, causar dano ao animal.
Segundo as coleçōes d'água mencionadas, os exemplares de pomáceas foram assim distribuídos :

\begin{tabular}{|c|c|c|c|}
\hline $\mathrm{Cu}$ & irso d'água & $\begin{array}{l}\text { 1. Introdução } \\
\text { (t/ag./1972) }\end{array}$ & $\begin{array}{l}\text { 2a Introduçāo } \\
\text { (16/ag./1972) }\end{array}$ \\
\hline Corrego & Biquinha & 1.000 & 1.450 \\
\hline ", & Grande & 0 & 680 \\
\hline$"$ & Olaria & 520 & 0 \\
\hline$"$ & Matos & 251 & 0 \\
\hline$"$ & Capão Fundo & 0 & 620 \\
\hline \multicolumn{2}{|c|}{ Vala $n^{\circ} 2$} & 520 & 0 \\
\hline \multicolumn{2}{|c|}{ Vala $n^{\circ} 5$} & 0 & 380 \\
\hline \multicolumn{2}{|l|}{ Total } & 2.291 & 3.130 \\
\hline
\end{tabular}

A distribuição das ponáceas foi imediatamente precedida de uma investigação relacionada à presença ou não de planorbíneos en todos os cursos nomeados - dando-se dez conchadas ao final de cada dez passos, e ai colocando-se também dez exemplares (ie Pomacea haustrum.

Após as introduçōes indicadas, somente a partir de julho/76 os cursos d’água de Baldim voltaram a ser regularmente pesquisados. Sem embargo, à população da cidade foi comunicada a introdução do predador-competidor, explicando-se o objetivo visado e solicitando-se que, na medida do possivel, fossem protegidos contra agressões intencionais.

4 - Estimativa da população de pilideos - Após introduzidos, em agosto/1972, a população de pomáceas só foi estimada em outubro/1978; portanto, 74 meses mais tarde. No caso, a estimativa da população foi realizada como indicado no item 2, porém extrapolando-se os dados numéricos obtidos; isto é, as densidades para área maior, ou seja, $1 \mathrm{~m}^{2}$.

Todos os moluscos pilideos, existentes en cada "quadrat" (amostra de $250 \mathrm{~cm}^{2}$ ) foram coletados, dimensionados e revertidos aos biótopos após as mensuraçijes.

\section{RESULTADOS}

1 - Fauna planorbinica - Apenas duas espécies de bionfalárias foram identificadas na localidade de Baldim: $B$. glabrata e $B$. straminea. A primeira delas não foi, entretanto, detectada no Córrego Matos e em três valas valas distintas. A segunda, mostrou-se presente só nos Córregos Grande e Matos (Tabelas 1 e 2). Por outro lado, os dados disponiveis sugerem que a população de $B$. straminea encontra-se confinada a nicho diverso do de $B$. glabrata.

2 - Infeção de planorbineos - Todos os espécimens capturados foram examinados por processo de esmagamento entre lâminas de vidro.

Em nenhuma ocasião detectou-se $B$. straminea abrigando cercárias de $S$. mansoni. $O$ total geral de individuos examinados foi igual a 399, não se incluindo, ai, os 10 exemplares coletados em outubro/1978 (Tabela 2).

A responsabilidade da transmissão e prevalência da esquistossomose na área deve-se à presença de $B$. glabrata suscetiveis. Nos anos de 1968,1970 e 1971 as percentagens de infecção oscilaram de $2,1 \%$ até 11,9\%. Após, no entanto, 1972 - ano 


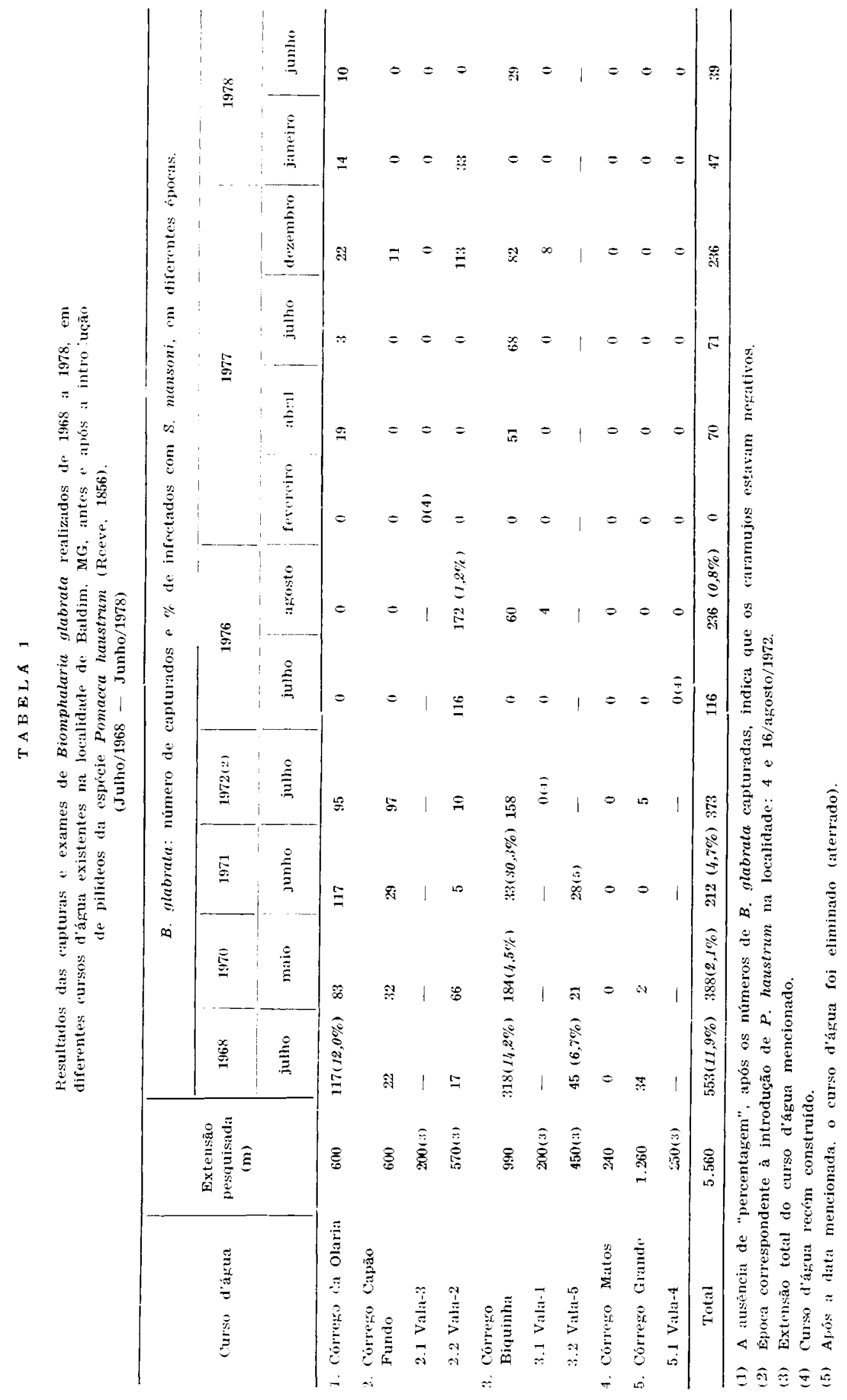




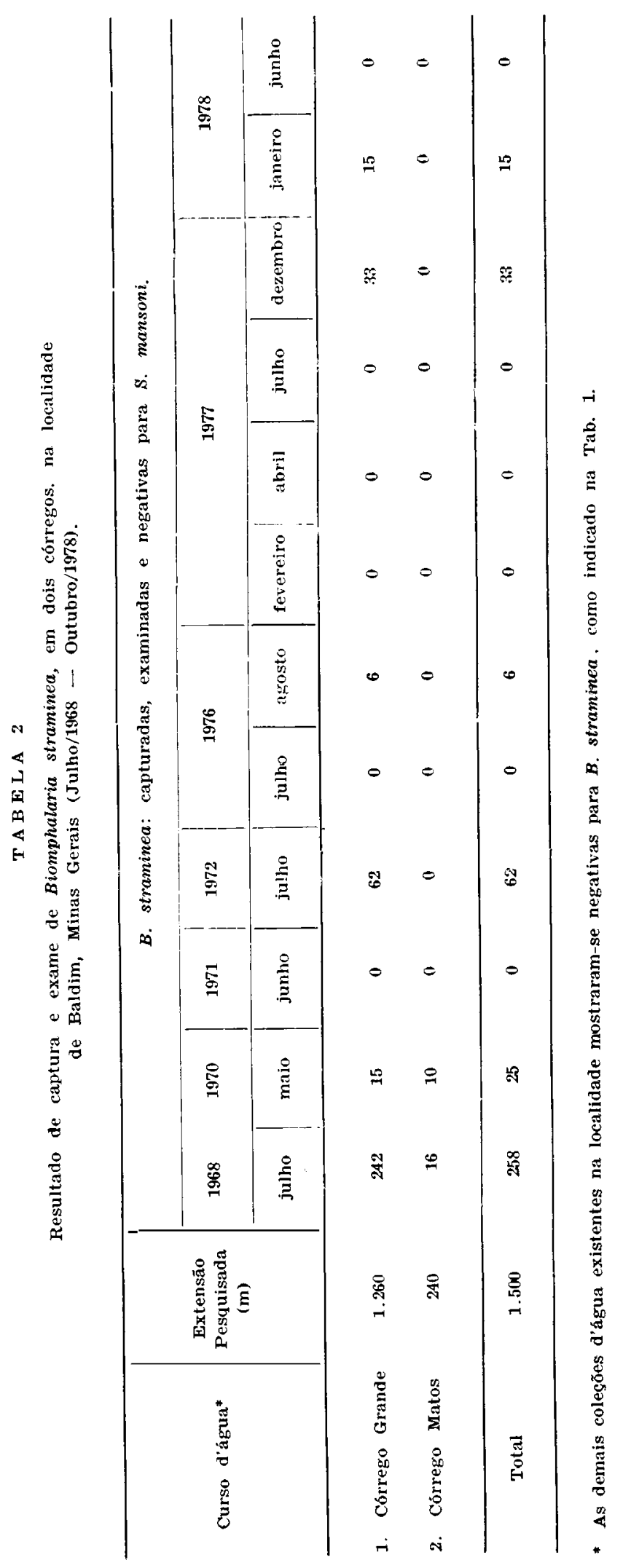




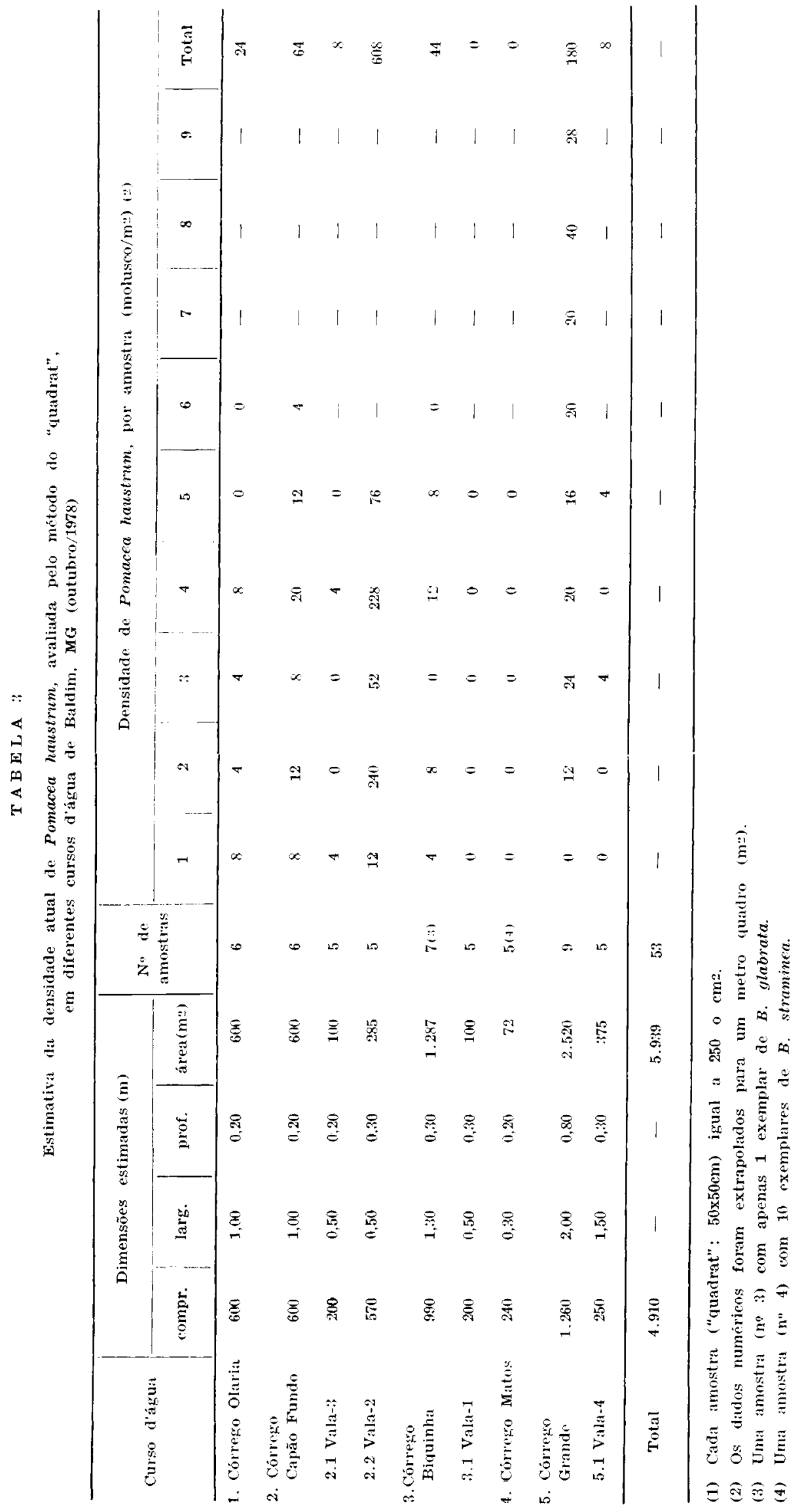


MILWARD-DE-ANDRADE, R. \& CARVALHO, O. dos S. Colonização de Pomacea haustrum (Reeve, 1856) em localidade com esquistossomose mansoni: Baldim, MG (Brasil). (Prosobranchia, Pilidae). Rev. Saúde públ., S. Paulo, 13:92-107, 1979.

da introdução de $P$. haustrum na localidade - uma única vez foram assinalados planorbineos parasitados: dois exemplares, provenientes de uma vala, em agosto/1976, entre 172 examinados (Tabela 1).
Em termos globais, os números de $B$. glabrata capturadas e examinadas, bem como a percentagem de positivas para cercárias de $S$. mansoni, em dez anos, foram os seguintes:

\begin{tabular}{|c|c|c|}
\hline $\begin{array}{c}\text { Data } \\
(1968-1978)\end{array}$ & $\begin{array}{c}\text { Capturados e } \\
\text { examinados } \\
\text { (No) }\end{array}$ & $\begin{array}{c}\text { Positivas } \\
(\%)\end{array}$ \\
\hline 1968: julho & 553 & 11,9 \\
\hline 1970: agosto & 388 & 2,1 \\
\hline 1971: junho & 212 & 4,7 \\
\hline 1972: julho & 373 & 0,0 \\
\hline 1976: julho & 116 & 0,0 \\
\hline agosto & 236 & 0,8 \\
\hline 1977: fevereiro & 0 & 0,0 \\
\hline abril & 70 & 0,0 \\
\hline junho & 71 & 0,0 \\
\hline dezembro & 236 & 0,0 \\
\hline 1978: janeiro & 47 & 0,0 \\
\hline junho & 39 & 0,0 \\
\hline Tutal & 2.341 & 3,7 \\
\hline
\end{tabular}

Os dados enumerados revelaram declínio da população de $B$. glabrata ao longo do tempo e, paralelamente, ausência de exemplares abrigando cercárias de $S$. mansont a partir de fevereiro de 1977.

Saliente-se, ainda, que as $4(30,8 \%)$ capturas realizadas de julho/68 a julho/72 proporcionaram $65,2 \% \quad(1.527)$ do total geral de bionfalárias daquela espécie. Em contrapartida, as $9(69,2 \%)$ coletas efetuadas de julho/76 a outubro/78 forneceram os $34,8 \%$ (816) restantes. Ou melhor, em 1976 a percentagem foi de $15,0 \%$ (352); em 1977, de $16,1 \%$ (377); e finalmente, em 1978 , de apenas $3,7 \%$ (87) de exemplares de $B$. glabrata.

A espécie $B$. straminea - ao que parece, refratária à cepa local do trematódeo ofereceu $84,4 \%$ (345) dos seus exemplares entre julho/68 a julho/72. Enquanto os $15,6 \%$ (64) restantes foram capturados após a introđução de pomáceas na localidade, ou seja, nas $9(69,2 \%)$ capturas procedidas de julho/76 a outubro/78 (Tabela 2).

\section{3 - População de Pomacea haustrum -} Como mencionado, em agosto/72, foram distribuidos, em cinco córregos e duas valas, 5.421 exemplares do pilideo em questão. A população expandiu-se, colonizando inclusive valas nas quais a espécie não havia sido intencionalmente colocada.

De agosto/72 até julho/76 não houve interferência ou capturas de moluscos na área. Coletas regulares de bionfalárias foram então retomadas, porém sem tocar intencionalmente na população de pomáceas, que se expandia.

Em outubro/78 procedia-se finalmente à estimativa da população de $P$. haustrum, através do método dos "quadrats", quer nos córregos quer nas valas - capturandose ao mesmo tempo os exemplares de bionfalárias presentes na área tomada como amostra.

Os dados que se seguem constituem estimativas de densidade das diferentes populaçōes surpreendidas nos biótopos men- 
MILWARD-DE-ANDRADE, R. \& CARVALHO. O. dos S. Colonização de Pomacea haustrum (Reeve. 1856) em localidade com esquistossomose mansoni: Baldim. MG (Brasil). (Prosobranchia, Pilidae). Rev. Saúde pübl., S. Paulo, 13:92-107, 1979.

cionados. Estabelecem, ainda, relação numérica entre a população introduzida em agosto/72 e a estimativa para outubro/78, segundo o mencionado método dos "quadrats".
De qualquer forma, evidenciam o aumento quantitativo da população - falando, pois, em favor do sucesso da colonização então induzida, com vistas ao controle biológico de $B$. glabrata.

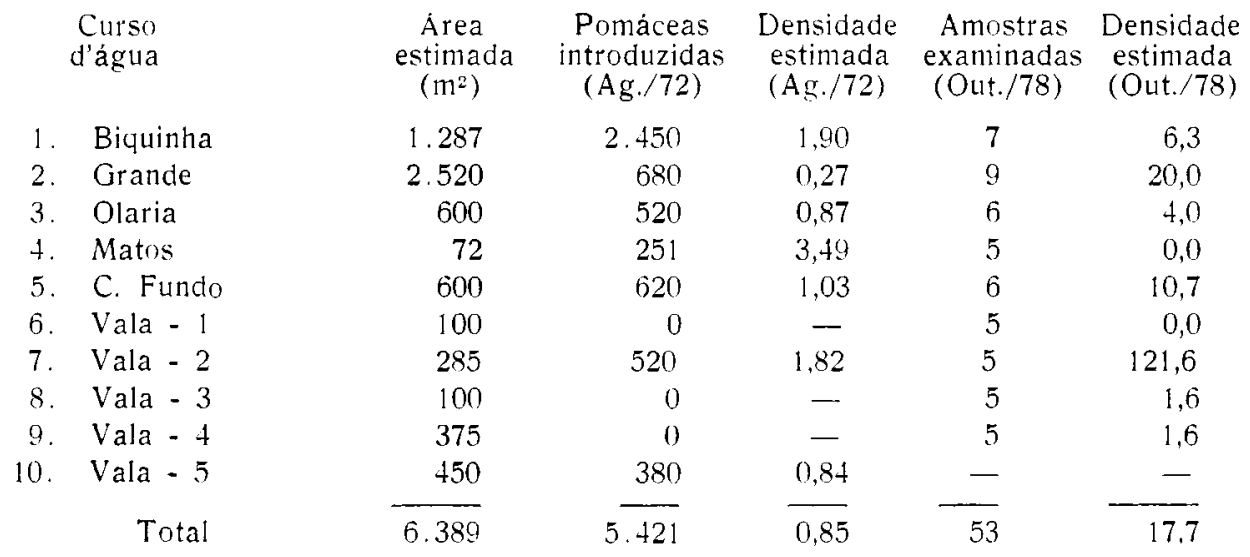

A fixaçăo da população na área em causa não ofereceu, entretanto, padrão uniforme. Observa-se, por exemplo, que no chamado Córrego Matos - pequeno curso com cerca de $0,30 \mathrm{~m}$ de largura média, no periodo seco - não foram detetados pilideos, em outubro/78; sen embargo, ai haviam sido introduzidos, em agosto/72, na proporção média de $3,49 / \mathrm{m}$. Também na Vala-1, eles mostraram-se ausentes. Porém, na Vala-2, intimamente conectada com 0 Córego Olaria, a densidade revelou-se expressiva: 121,6 pomáceas/m².

Nas Valas 3 e 4 , a densidade estimada foi da ordem de 1,6 pilideos $/ \mathrm{m}^{2}$, ou seja, o menor registro entre os cursos investigados. $\mathrm{Na}$ de número 5 , não há dados, pois desapareceu por força de alteraçōes no terreno.

O Córrego Grande constitui o principal curso hidrico da localidade, sendo alimentado, inclusive, pelos Córregos Olaria, Capão Fundo e Biquinha (ver "croquis"). Tem cerca de $2,00 \mathrm{~m}$ de largura e águas que fluem continuamente, serpenteando sob a luz do sol ou, eventualmente, recobertas em parte por vegetação hidrófila: Heteranthera reniformis, Myriophylum brasiliensis, gramineas, ciperáceas, e outras. (Fig. 1). É freqüentado pelas crianças da localidade; pelas lavadeiras e pequenos grupos de camponeses ou habitantes periféricos que ai praticam, com intensidade não mensurável, a pesca de lazer. O curso serve também de bebedouro de animais: bois, cavalos, e c frequentado por aves migradouras.

A população atual de pomáceas no Córrego Grande - malgrado o arraste periodico à época das chuvas: outubro a abril - é facilmente observável. Em termos concretos, a estimativa indicou expressão numérica de ordem de 20,0 exemplares $/ m^{2}$.

Antes da introdução do molusco predador-competidor, naquele biótopo podiam ser visualizados continuos "pontos negros" que marcavam a presença de $B$. glabrata, facilmente capturáveis com pinças, conchas, etc.

Presentemente, os "pontos negros" sāo constituidos por exemplares de $P$. hallstrum, com dimensōes variáveis. Deslizam no substrato, onde deixam sulcos; ai tambem 
MILWARD-DE-ANDRADE, R. \& CARVALHO, O, dos S. Colonização de Pomacea hausirum (Reeve, 1856) em localidade com esquistossomose mansoni: Baldim. MG (Brasil). (Prosobranchia. Pilidae). Rev. Saude publ., S. Paulo, 13:92-107, 1979.

enterram-se e permanecem imóveis durante longo tempo; prendem-se a fragmentos de rochas ou outros materiais; depositam seus ovos cor-de-rosa, em aglomerados que eventualmente podem conter mais de setecentas unidades, no solo ribeirinho ou nas hastes vegetais emersas, principalmente. Não atacam diretamente os planorbineos de maior porte, porém predam-lhes os ovos e os jovens recém-eclodidos. Extremamente vorazes, encontram no Córrego Grande abundante alimentação, decorrente da eutroficação consequente ao aporte de esgostos domésticos.

Também nos Córregos Biquinha e Capão Fundo a população atual do predador é numericamente sensivel: 6,3 e 10,7 exemplares $/ \mathrm{m}^{2}$. No Córego Olaria, a estimativa foi da ordem de 4,0 pomáceas $/ \mathrm{m}^{2}$. No primeiro dos citados, saliente-se, foi capturado também um exemplar de $B$. glabrata.

$\mathrm{Na}$ verdade, aquele espécimen constituiu um registro solitário, pois foi o único detectado durante os trabalhos efetuados para estimar a população de pomáceas, segundo o método dos "quadrats".

\section{DISCUSSAO}

O controle biológico natural de populações, animais e vegetais, é processo implícito ao funcionamento dos ecossistemas e associa-se à idéia de competição - cuja descoberta científica constituiu ponto de partida para o desenvolvimento da clássica proposição de Darwin e Wallace sobre a origem das espécies.

A introdução de competidores para controlar espécies indesejáveis é prática bastante antiga, porém o desenvolvimento de técnicas apropriadas origina-se da adequada aplicação do método científico no estudo da natureza. Historicamente, as primeiras tentativas bem sucedidas datarian do último quarto do século passado, creditando-se aos entomologistas os primeiros e indiscutiveis resultados práticos (Aragão, 1 Huffaker 8 ).

No nosso meio, a estudo biológico e eculogico sistematizados de predadores $e$ competidores de planorbíneos tem sido desenvolvido no Laboratório de Ecologia do Centro de Pesquisas "René Rachou"/FlOCRUZ. Os resultados aqui apresentados decorrem de atividades suportadas, em parte, pelo Conselho Nacional de Desenvolvimento Científico e Tecnológico (CNPq), porém complementar às investigaçōes já anteriormente desenvolvidas (Milward-deAndrade 16.18,19,24; Milward-de-Andrade e Carvalho 25 ; Milward-de-Andrade e Guimarães ${ }^{26}$; Milward-de-Andrade e col.27.29.

Os resultados alcançados com a introdução de Pomacea haustrum na localidade de Baldim mostram, em primeiro lugar, que os exemplares introduzidos adaptaram-se prontamente às condiçóes lóticas ou de águas correntes e deram origem a novos descendentes, vencendo, pois, as pressōes seletivas ambientais. Ao que parece, os pilideos terāo se fixado permanentemente na localidade, alcançando altas densidades e não revelando até aqui inconvenientes secundários.

Resultados promissores de competição e, mesmo, substituição de populações de planorbineos por pilideos têm sido comunicados, registrando-se tambén desapontamentos - estes, sempre esperados quando os novos ambientes a serem colonizados não apresentam ecótones apropriados e possi- 
MILWARD-DE-ANDRADE, R. \& CARVALHO. O. dos S. Colonização de Pomacea haustrum (Reeve, 1856) em localidade com esquistossomose mansoni: Baldim, MG (Brasil). (Prosobranchia, Pilidae), Rev. Saúde públ., S. Paulo, 13:92-107, 1979.

bilidades de deslocamento para satisfazer a necessidade de ovoposição (Milward-deAndrade, $\left.{ }^{1 i}\right)$. Os pilideos são também vítimas de predação, por exemplo, de roedores de hábitos semi-aquáticos; do passeriforme tiranideo: Pitangus sulphuratus (L.) ou ben-te-vi; do falconiforme acipitrideo: Rostrhamus sociabilis (Vieil.) ou gaviãocaramujeiro; dos gruiformes ralídeos: Laterallus spp. ou frangos d'água; dos anseriformes anatideos: Cairina moschata (L.) ou pato-do-mato, de Anas spp. ou imarrequinhas; do caradriforme jacanideo: Jacana spinosa jacana (L.) ou jaçanã. Sendo dificil o acesso à orla de certas lagoas, a captura de conchas de pilídeos pode ser feita junto a moirões de cerca: nas suas frestas ou no chão, pois o bemte-vi freqüentemente para aí os transportam e nesse local os comem.

A colonização procedida e aqui relatada mostra, por outro lado, redução progressiva da população de Biomphalaria glabrata após a introdução de Pomacea haustrum na localidade - o que, no caso, sugere estreita relação de causa e efeito. Não se pretende, entretanto, afirmar que os planorbíneos serão efetivamente eliminados da área em questão - malgrado possam, inclusive, ser expulsos de diferentes biótopos, cujos nichos passarão a ser ocupados pelos pilídeos.

No caso da localidade de Baidim, a redução da população de bionfalárias fez-se notar nos índices de infecção do trematódeo S. mansoni. De fato, a última amostra positiva foi detectada en agosto/ 76 , isto é, $2(0,8 \%)$ exemplares entre 236 capturados eliminavan cercárias daquele platelminto.

É de se acreditar que o controle da esquistossomose mansoni, através dos moluscicidas disponiveis - salvo em particularissimas situações - é política absolutamente condenável, por motivos biológicos, principalmente.

De fato, há a recordar que os planorbíneos também são vitimas da parasitose, introduzida no Continente Americano. Eles são, ainda, membros importantes da biocenose de diversos ecossistemas. Sua expulsão pura e simples deve implicar o preenchimento adequado do nicho vacante - imprevisivel no caso da utilização de biocidas quimicos, mas passiveis de controle quando ocupado por organismo bioecologicamente definido.

O ideal maior não será propugnar, ingenuamente, pela extinção (sic) dos planorbíneos, mas antes procurar nos métodos de controle biológico soluções ecologicamente aceitáveis - capazes, em suma, de minimizar a expansão atual e as altas taxas de prevalencia da endemia, que ocorre em nusso meio. Ou, ainda, conscientizar as populações humanas envolvidas, buscando justamente no seu seio as soluções reclamadas. Vale dizer, abolindo medidas paternalistas inconsequientes e frustrantes, ou a enganosa proposição de tratamento enı massa - que atende apenas ao interesse da indústria farmacêtutica multinacional. 
MILWARD-DE-ANDRADE. R. \& CARVALHO O dos S. Colonização de Pomacea hrusinum (Reere, 1856) em localidade com esquistossomose mansonl. Baldim, MG (Brasil). (Prosobranchia, Pilidae), Rer. Saúde públ., S. Paulo, 13.92-107. 1979.

Mil. MARD-DE-A.NDRADE, R. \& CARYalHo, O. dos S. /Colonization of Pomacea haustrum (Reeve, 1856) at localitity with Schistosomiasis mansoni: Baldim, MG (Brazil)] Rev. Saúde públ., S. Pallo, 13:92-107, 1979.

ABSTRACT: In the region of Baldim, $M G$ (Brazil) - a well-known Schistcsoma mansoni endemic area where transmission control had already been unsuccessfully' attempted through molluscicide, sanitary education and clinical treatment - 5,421 specimens of Ponnacea haustrum (Prosobranchia, Pilidae) were introduced into 5 brooks and 2 ditches where Biomphalaria glabrata (primarily) and $\mathrm{B}$. straminea (secondarily) predominated. From 1968 to 1971 , the infection rate of $\mathrm{B}$. glabrata by S. mansoni ranged from $2.1 \%$ to $11.9 \%$. None of the $\mathrm{B}$. straminea specimens collected, however, were seen to be liberating cercariae of this trematode. After the introduction of Pilidae, only once were two positive B. glabrata specimens $(1.8 \%$ ) detected. A decrease in the planorbide population was observed, as well as an increase in the pomacea density to 20.0 and 121.6 specimens per square meter in the brooks and ditches, respectively. P. haustrum density was estimated by the "quadrat" method. Of the planorbides in the experiment, $65.2 \%(1,526)$ were collected from lally/68 to lully/72 and the rest were obtained after the introduction of the predotor-competitor species, as follows: $15.0 \%$ (352) in 1976; 16.1\% (377) in 1977; and 3.7\% (87) in 1978 . Although transterred from a lenitic meditm (Sete Lagoas, MG), the pomaceae became perfectly adapted to the lotic collections of $\bar{B}$ aldim, and proved to be capable of replacing the original B. glabrata populations of several biotopes or. at least, of becoming predominant, with no damage to the new ecosystems. Based on the data presented above and the knowledge previously acquired in the study of the biolog! and ecolog! of the species, it is believed that, under similar conditions, Pomacea haustrum (Reeve, 1856) - and, by extension, P. lineata (Spix. 1827) and P. canaliculata (Lamarck, 1822), as well as other species from the same genus - may be successfully used in the biological control of the intermediate hosts of $\mathrm{S}$. mansoni.

UNITER.us: Pomacea haustrum. Schistosomiasis, biological control.

\section{REFEREXCIAS RIBLIOGRAFICA}

1. ARAGAO. M. B. Equilibrio da natureza e controle biológico. Rer. bras. Matar. $19 \cdot 655-95,1967$.

2. CARVALHO. O. S. et al. Efferts of gammaradiation on eggs of Pomacea haustrum (Reeve 1843) from Pampulha Lake. Belo Horzonte, MG (Brasili. Rer. bras. Biol., 34:565-72, 1971.

?. COTTINHO, L. M. O conceito de cerrado. Rex. bras. Bot., 1.1723. 1978.

4. FAUSTO F. J. Notas sobre biologia do aruá Ponacea hatstrum iReere!. Bol. Soc. cear. Afron., 3:43-8, 1962.

5. FAUSTO F\%. J. Sobre o número de posturas do aruá Pomacea haustrum (Reeve) (Molusca, Mesogastropoda), Bor. Soc. cear. Agron., 6:43-7, 1965.
6. FErguson, F. F. et al. Potencial for blological control of Australorbis glabratus, the intermedate host Puerto Rican schistosomiasis. Amer, J. trop. med. Hyg., $7: 491-3,1958$.

7. GLIMARAES. C. T. Obserrcẹos bioecologicas sobre Pomacea haustrum (Reeve, 1856). Sua utulizaçao i.s controle biológico da esquistossomose mansoni. Belo Horizonte, 1978. [D1ssertação de Mestrado - Universidade Federal ce Minas Gerais]

8. HufFAKER, C. B. Biological control. New York. Plenun Press, 1971.

9. KATZ. N. Clinical evaluation of niridazole and hycanthone in schistosomiasis mansoni in endemic areas. J. Toxicol. environ. Hith, 1:203-9, 1975. 
MILWARD-DE-ANDRADE, R. \& CARVALHO, O. dus S. Colonização de Pomacea haustrum (Reeve, 1856) em localidade com esquistossomose mansoni: Baldim, MG (Brasil). (Prosobranchia, Pilidae). Rev. Saúde públ., S. Paulo, 13:92-107, 1979.

10. KATZ, N. et al. An attempt to control schistosomiasis in an endemic ares by combining clinical treatment and molluscicide application. [Apresentado ao II International Congress Parasitology. Washington, 1970]

11. KOEPPEN. W. Climatologia. México, Fondo de Cultura Economica. 1948.

12. LOPES, H. S. Sobre duas espécies do gènero Pomacea Perry, com um estudo da genitália de ambos os sexos. Rev. bras. Biol., 15:203-10, 1955.

13. LOPES, H. S. Sobre Pomacea canaliculate (Lamarck, 1822) (Mesogastropoda. Architaenioglossa, Mollusca) Rev. bras. Biol., 16:535-42, 1956.

14. LOPES. H. S. Sobre Pomacea lineata (Spix, 1827) (Mesogastropoda. Architaenioglossa. Mollusca). Rev bras. Biol. $16: 375-80$, 1956 .

15. MATTHIESEN, F. A. Pomacea lineata (Spix, 1827) (Mollusca. Prosobranchia) e o combate a planorbídeos, Cien. Cult., 28:777, 1976.

16. MILWARD-DE-ANDRADE, R. Biological control of Schistosoma mansoni intermediate host through Pomacea haustrum (Reeve, 1856). In: International Congress of Parasitology. 3rd, Munchen, 1974. Proceedings. Munchen. 1974. v. 2. p. 827 .

17. MILWARD-DE-ANDRADE, R. Competıção entre Pomacea haustrum e Biomphalaria glabrata, em condições de laboratório. [apresentado ao 1o Encontro de Pesquisa do ICB-UFMG. Belo Horizonte, 1971]

18. MILWARD-DE-ANDRADE, R. Controle biológico da esquistossomose mansoni. Rev. Soc. bras. Med. trop., 6:421, 1972 .

19. MILWARD-DE-ANDRADE, R. Controle biológico de Biomphalaria giabrata (Say, 1818) através da utilização de Pomacea haustrum (Reeve, 1856). Ciên. Cult., 24(Supl.):374-5, 1972.

20. MILWARD-DE-ANDRADE, R. Nota ecológica sobre o Lago da Pampulha (Belo Horizonte, MG), com especial referência aos planorbídeos, Rev. bras. Malar., 21:59-116, 1969.
21. MILWARD-DE-ANDRADE, R. Notes on laboratory and field observations regarding planorbides competitors and predators: Protozoans, Crustaceans and Mollusks, Rev. bras. Malar., 23:193-4. 1971.

22. MILWARD-DE-ANDRADE. R. O problema da esquistosomose mansoni no $\mathrm{La}$ go da Pampulha. Belo Horizonte, MG (Brasil). Rev, bras. Malar., 11:65:3-74, 1959.

23. MILWARD-DE-ANDRADE. R. Situação atual da limnologia, piscicultura $e$ pesca continental no Estado de Minas Gerais (1975). In: Encontro Nacional de Limnologia, Piscicultura e Pesca Continental, 19, Belo Horizonte. 1975. Anais. Belo Horizonte, Fundação J. Pinheiro, Secretaria de Planejamento Org. Geral, 1975. p. 387-401.

24. MILWARD-DE-ANDRADE, R. Tentativa de colonização de lagoas do "Quadrilátero Ferrifero" (Nova Lima. MG. Brasil) com Pomacea haustrum (Reeve. 1856). In: Congresso da Sociedade Brasileira de Medicina Tropical, 14 Congresso da Sociedade Brasileira de Parasitologia, 3, J oão Pessoa, 1978. Resumos de temas livres. João Pessoa, 1978. p. 161.

55. MILWARD-DE-ANDRADE, R. \& CARVALHO. O. dos S. Colonização de Pomacea haustrum em localidade com esquistossomose mansoni. (Baldim, MG. Brasil). Ciên. Cult., 29(supl,):787. 1977.

26. MILWARD-DE-ANDRADE, R. \& GUIMARÃES, C. T. Colonização de Pomacea haustrum (Reeve, 1856) em lagoa situada em área de cerrado (Esmeraldas. MG. Brasil). In: Congresso da Sociedade Brasileira de Medicina Tropical. 140 e Congresso da Sociedade Brasileira de Parasitologia, $3^{\circ}$, João Pessoa. 1978. Resumos de temas livres. João Pessoa, 1978. p. 153.

27. MILWARD-DE-ANDRADE. R. \& GUIMARĀES, C. T. Ecologia de Pomacea haustrum (Reeve, 1843) no Lago da Pampulha, Belo Horizonte, MG. [apresentado ao I Encontro de Pesquisa do ICB-UFMG, Belo Horizonte. 1971]

28. MILWARD-DE-ANDRADE, R. \& GUIMARAES, C. T. Introdução de Pomacea haustrum (Reeve, 1843) em biótopos de 
MILWARD-DE-ANDRADE, R. \& CARVALHO, O. dos S. Colonização de Pomacea haustrum. (Reeve, 1856) em localidade com esquistossomose mansoni: Baldim. MG (Brasil). (Prosobranchia. Pilidae). Rev. Saúde públ., S. Paulo, 13:92-107. 1979.

hospedeiros intermediários de Schstosoma mansoni. Ciên. Cult., 2r(supl.): 405. 1975 .

29. MILWARD-DE-ANDRADE. R. et al, Alguns dados bioecológicos de Pomacea haustrum (Reeve. 1856), predadol-competidor de hospedeiros intermediários de Schistosoma manson Sambon, 1907. Rer, Saide publ., S. Paulo, 12.78-89. 1978 .

30. MILWARD-DE-ANDRADE. $R$, et al. Repopulação natural e índices de infecção de planorbíneos. após aplicação de moluscicida e tratamento em massa da população humana em área endêmica de esquistossomose mansoni. Rer. bras. Malar., 23:205-7, 1971.

31. SCOTT, M. I. H. Estudio morfologico y taxonomico de los Ampullaridos de la Republica Argentina. Rer. Mus, argent. Cren. nat. Bernardino Ruadara, 3. 253-333. 1957.

Recebido nara publicaşão em 20/12/1978

Aprovalo vara publicação em $22 / 03 / 1979$ 